\title{
Frontal dynamics boost primary production in the summer stratified Mediterranean Sea
}

\author{
Antonio Olita • Arthur Capet - Mariona \\ Claret • Amala Mahadevan - Pierre Marie \\ Poulain • Alberto Ribotti . Simón Ruiz . \\ Joaquín Tintoré · Antonio Tovar-Sánchez • \\ Ananda Pascual
}

Received: date / Accepted: date

\begin{abstract}
Bio-physical glider measurements from a unique process-oriented experiment in the Eastern Alboran Sea (AlborEx) allowed us to observe the distribution of the deep chlorophyll maximum (DCM) across an intense density front, with a resolution $(\sim 400 \mathrm{~m})$ suitable for investigating sub-mesoscale dynamics. This front, at the interface between Atlantic and Mediterranean waters, had a sharp density gradient $\left(\Delta \rho \sim 1 \mathrm{~kg} / \mathrm{m}^{3}\right.$ in $\sim 10 \mathrm{~km}$ ) and showed imprints of (sub-)mesoscale phenomena on tracer distributions. Specifically, the chlorophyll-a concentration within the DCM showed a disrupted pattern along isopycnal surfaces, with patches bearing a relationship to the stratification (buoyancy frequency) at depths between 30 and $60 \mathrm{~m}$.
\end{abstract}

A. Olita

National Research Council, Institute for Coastal Marine Environment (IAMC-CNR),

E-mail: antonio.olita@cnr.it

A. Capet

MAST, University of Liège, Belgium

E-mail: arthurcapet@gmail.com

P.M. Poulain

OGS, Trieste, Italy

M. Claret

JISAO/UW, Seattle, WA, USA

A. Tovar-Sánchez

ICMAN, Puerto Real, Spain

A. Ribotti

IAMC-CNR, Oristano, Italy

A. Mahadevan

Woods Hole Oceanographic Institution, MA, USA

A. Pascual, S. Ruiz,

IMEDEA(CSIC-UIB), Esporles, Spain

J. Tintoré

IMEDEA(CSIC-UIB), Esporles, Spain

SOCIB, Mallorca, Spain 
In order to estimate the primary production (PP) rate within the chlorophyll patches observed at the subsurface, we applied the Morel and Andrè (1991) biooptical model using the Photosynthetic Active Radiation (PAR) from Argo profiles collected simultaneously with glider data. The highest production was located concurrently with domed isopycnals on the fresh side of the front, suggestive that (sub-)mesoscale upwelling is carrying phytoplankton patches from less to more illuminated levels, with a contemporaneous delivering of nutrients. Integrated estimations of PP $\left(1.3 \mathrm{~g} \mathrm{C} \mathrm{m}^{-2} \mathrm{~d}^{-1}\right)$ along the glider path are two to four times larger than the estimations obtained from satellite based algorithms, i.e. derived from the 8-days composite fields extracted over the glider trip path. Despite the differences in spatial and temporal sampling between instruments, the differences in PP estimations are mainly due to the inability of the satellite to measure DCM patches responsible for the high production. The deepest (depth $>60 \mathrm{~m}$ ) chlorophyll patches are almost unproductive and probably transported passively (subducted) from upper productive layers.

Finally, the relationship between primary production and oxygen is also investigated. The logarithm of the primary production in the DCM interior $(\mathrm{Chl}>0.5$ $\mathrm{mg} / \mathrm{m}^{3}$ ) shows a linear negative relationship with the Apparent Oxygen Utilization, confirming that high chlorophyll patches are productive. The slope of this relationship is different for Atlantic, mixed interface waters and Mediterranean waters, suggesting the presence of differences in planktonic communities (whether physiological, population or community level should be object of further investigation) on the different sides of the front. In addition, the ratio of optical backscatter to $\mathrm{Chl}$ is high within the intermediate (mixed) waters, which is suggestive of large phytoplankton cells, and lower within the core of the Atlantic and Mediterranean waters. These observations highlight the relevance of fronts in triggering primary production at DCM level and shaping the characteristic patchiness of the pelagic domain. This gains further relevance considering the inadequacy of optical satellite sensors to observe DCM concentrations at such fine scales.

Keywords Primary production · Glider · Mediterranean Sea · Fronts · submesoscale $\cdot \mathrm{AOU}$

\section{$1 \quad 1$ Introduction}

2 Primary production in seas and oceans is crucial for both ecosystem functioning, since it regulates the available energy for higher-trophic-levels, and global warming, as it affects carbon export and sequestration. An interesting scientific debate is on the table about the mechanisms behind bloom initiation in temperate regions, classically explained by the seminal Critical Depth theory by Sverdrup (1953). Some recent studies proposed alternative (Behrenfeld, 2010, Dilution Recoupling hypothesis) or complementary (Huisman et al, 1999; Chiswell, 2011; Taylor and Ferrari, 2011a, Critical Turbulence) explanations of the bloom onset and the modulation of the primary production during the spring bloom.

Other recent studies focused on the role of mesoscale and submesoscale dynamics in the crucial phase of bloom or early-bloom triggering (Mahadevan et al, 2012; Taylor and Ferrari, 2011b), emphasizing the relevance of dynamical processes at various scales in creating the conditions for producers to exceed consumption/export. 
A short and focused synthesis of this debate was recently provided by Franks (2014) while Chiswell et al (2015) attempted to shed light on these apparently mutually exclusive theories through a simple theoretical model reproducing the annual cycle of phytoplankton and checking how the model behavior could be explained by such different theoretical frames.

While the above-mentioned debate remains open, even less is known about the mechanisms driving and controlling primary production, and its related biomass, during the post-bloom period, i.e. during summer stratification and before the onset of winter mixing and disruption of such stratification.

In temperate areas, once the seasonal thermal stratification has set in, the newly formed upper mixed layer (UML) becomes naturally nutrient depleted. The phytoplankton community continues to live and reproduce in sub-surface layers, tightly associated with the nitracline. It is commonly assumed that this layer is within the pycnocline, below the UML, forming the so called deep chlorophyll maximum (DCM, hereafter) otherwise called sub-surface maximum. This is an ubiquitous feature of temperate regions of the world oceans. Processes and mechanisms underlying the vertical position of the DCM in the different parts of the world oceans and seas have been explored (Hodges and Rudnick, 2004), but still unclear. Recently Navarro and Ruiz (2013) observed a tight relationship between the potential density of the waters in which the spring bloom appears and the DCM pycnal location, suggesting that the DCM localization would be better described in the vertical using isopycnal coordinates than fixed depth levels. Primary production associated with the DCM has been less explored than its winter-spring counterpart, when surface blooms have been broadly assessed both in biomass and production through satellite based studies (e.g. Antoine et al, 1996; Behrenfeld and Falkowski, 1997). Satellite optical sensors are able to provide data up to $\sim 1 / 5$ of the euphotic depth (Siswanto et al, 2005). This implies that algorithms for estimation of integrated (throughout the euphotic depth) primary production usually rely on a uniform vertical distribution of the Chl (here used as proxy for phytoplankton biomass) (e.g. Platt, 1986) for the "mixed" case (winter conditions) or on a Gaussian vertical distribution to mimic the DCM conditions (e.g. Platt et al, 1991). Gaussian modeling actually can mimic DCM presence, but is not able to describe the peaks often responsible for DCM and also visible in the present data. We consider that the DCM outcropping events are not frequent enough so as to imprint the average satellite perception sufficiently to account for the persistent DCM maximum PP. The present cases is a clear example where the DCM was brought close to the surface, yet, the PP underestimation by the satellite remains. On the contrary, in these case such underestimation can be even larger, considering that in normal conditions gaussian modeling can mimic DCM presence but in presence of strong vertical dynamics as along frontal regions.

In the Mediterranean Sea the DCM was firstly investigated during the early nineties of the past century (e.g. Varela et al, 1992; Delgado et al, 1992; Raimbault et al, 1993). Estrada (1996) found chlorophyll-a concentrations exceeding $2 \mathrm{mg} / \mathrm{m}^{3}$ in the Balearic area, recording a tight relationship of the DCM position with the nitracline depth. Very close to the location of the present study (Alboran Sea), Moran et al (2001) found DCM of about $1.4 \mathrm{mg} / \mathrm{m}^{3}$ through a mesoscale resolving sampling cruise based on CTD and bottle measurements in October 1996. Authors estimated in the same study production maxima not exceeding 2 $\mathrm{g} \mathrm{C} \mathrm{m}^{-2} \mathrm{~d}^{-1}$. Similar values of productivity were found by Videau et al (1994) for 
the close Almeria-Oran front in the same period of the year while Rodríguez et al (1998) showed that mesoscale features shape the size-structure of the phytoplankton community in the Alboran Sea. Moreover, idealized modelling studies report up to ten fold local increases of productivity by submesoscale dynamics in frontal regions (Lévy, 2008; Lévy et al, 2012) due to large vertical velocities (Mahadevan and Tandon, 2006). This dynamics can be specially relevant during stratified periods, when phytoplanktonic biomass concentrates in low-light layers.

In this framework, the new generation of underwater autonomous vehicles assume an important role as they are able to resolve the submesoscale phenomena, acting at $1-10 \mathrm{~km}$ scales. In the present study, high-resolution bio-physical observations (temperature, salinity, fluorescence, turbidity, and dissolved oxygen) were collected by a Slocum glider that traversed an intense front in the eastern Alboran Sea. Glider measurements captured the sub-mesoscale distribution of the DCM across the intense density front, which highlights the role of frontal dynamics. Primary production estimates, obtained through a bio-optical model based on the glider data and synchronous bio-Argo measurements (PAR, Chl, Oxygen, Temperature, Salinity, Turbidity), allowed us to associate local frontal processes with production and export estimates. Analysis of dissolved oxygen profiles also provided important information on the biological and physical processes occurring at the front, supporting the interpretation of the bio-optical primary production estimates.

\section{Materials and Methods}

\subsection{Gliders}

Two gliders, a deep and shallow Slocum glider (hereafter DG and SG respectively), were deployed during the interdisciplinary, multi-platform process oriented study, AlborEx (Ruiz et al, 2015; Pascual et al, 2017), carried out during the period 25-31 May, 2014 (see Fig.1). Gliders SG and DG profiled to a depth of $200 \mathrm{~m}$ (as part of the Jerico-TNA proposal denominated FRIPP) and $500 \mathrm{~m}$, respectively, measuring temperature, salinity, oxygen, turbidity and fluorescence. The sampling strategy was based on two parallel north-to-south transects, $10 \mathrm{~km}$ apart. Intense currents, related to the frontal area, advected gliders eastward and the sampling strategy (initially planned as a repeated round trip along the same route) was modified in real time. Gliders performed several transects crossing the frontal zone, but also moving eastward following the main stream direction, bordering an eddy. SG sampled the ocean at an approximate horizontal resolution (at surface) of $0.4 \mathrm{~km}$ (about $1 \mathrm{~km}$ for DG), thus achieving approximately 38 (14 for DG) dives per day. Glider data processing includes thermal lag correction for salinity following the methodology described in Garau et al (2011).

\subsection{Profiling floats}

During AlborEx, three profiling floats (Arvor-C, Arvor A3 and Prov-Bio) were deployed in a straight line along the frontal zone, a few kilometers apart from each other. The Arvor-C was programmed with $3 \mathrm{~h}$ cycles down to $400 \mathrm{~m}$. The Arvor-A3 was initially configured to have daily cycles. At the end of the cruise, it 


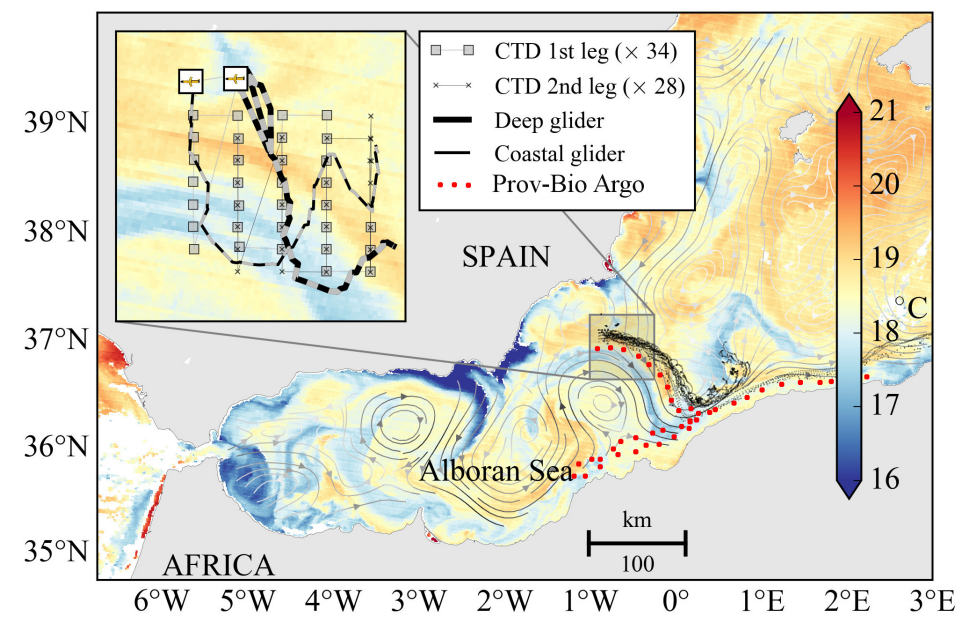

Fig. 1 Sampling strategy of AlborEx experiment: Glider, CTD and Prov-Bio float tracks are shown. Modified from Pascual et al (2017).

was left at sea and its cycle was changed to 5 days (MedArgo standard, Poulain et al, 2007) using the downlink of the Argos 3 telemetry. Both the Arvor-C and Arvor-A3 measured temperature and conductivity (salinity) in the water column. The Prov-bio float had initial daily cycles synchronized to profile near local noon time. It was left at sea after the campaign and its cycle was changed to 5 days using the Iridium downlink. In addition to temperature and salinity, the Prov-bio measured dissolved oxygen, Chlorophyll-a (converted from fluorescence), CDOM, backscattering at $700 \mathrm{~nm}$, downwelling irradiance at 380, 410, $490 \mathrm{~nm}$ and PAR. The Prov-bio float measurements have been essential in order to calibrate an empirical model to estimate PAR from depth and Chlorophyll-a (Chl, hereafter) concentration (together with surface PAR obtained from atmospheric models, see below) collected by the gliders.

\subsection{Bottle samples and Chl measurements}

Samples for Chl and nutrients $\left(\mathrm{NO}_{2}^{-}, \mathrm{NO}_{3}^{-}, \mathrm{PO}_{4}^{3-}\right)$ analysis were collected during the cruise at eight depths $(5,20,40,60,90,100,120,150 \mathrm{~m})$ in 66 stations, using 10 L Niskin bottles mounted on a Sea-Bird SBE32 rosette sampler. At each station and depth one liter of water was filtered through a Whatman GF/F glass fiber filter for total Chl estimation. Chlorophyll concentrations were determined fluorimetrically (Holm-Hansen et al, 1965) using a Trilogy Turner Design fluorimeter after pigment extraction with $90 \%$ acetone for 24 hours in the dark at $4^{\circ} \mathrm{C}$.

Although bottle data are not the focus of the present study, chlorophyll bottle measurements provided reference values to compare with glider-based estimates of Chl, as both Glider and float fluorimeters were originally calibrated by the manufacturer and no cross-calibration was performed before the cruise. Chl maxima detected through bottle measurements are comparable (slightly exceeding $5 \mathrm{mg} / \mathrm{m}^{3}$ ) to Chl maxima estimated through the fluorimetric method by the DG samplings 
(see Fig.2). SG records of chlorophyll maxima are lower than DG records, with values of about $3.5 \mathrm{mg} / \mathrm{m}^{3}$, comparable to values found by Moran et al (2001). The discrepancy of the values between the two Gliders might be related to the spatial and temporal variability of the Chlorophyll field. The Chl measurements performed with the three different platforms (2 gliders, Prov-Bio Argo float, bottle direct measurements) are comparable in terms of density distribution and magnitude (all platforms showing maxima around $5 \mathrm{mg} \mathrm{m}^{-3}$ ).

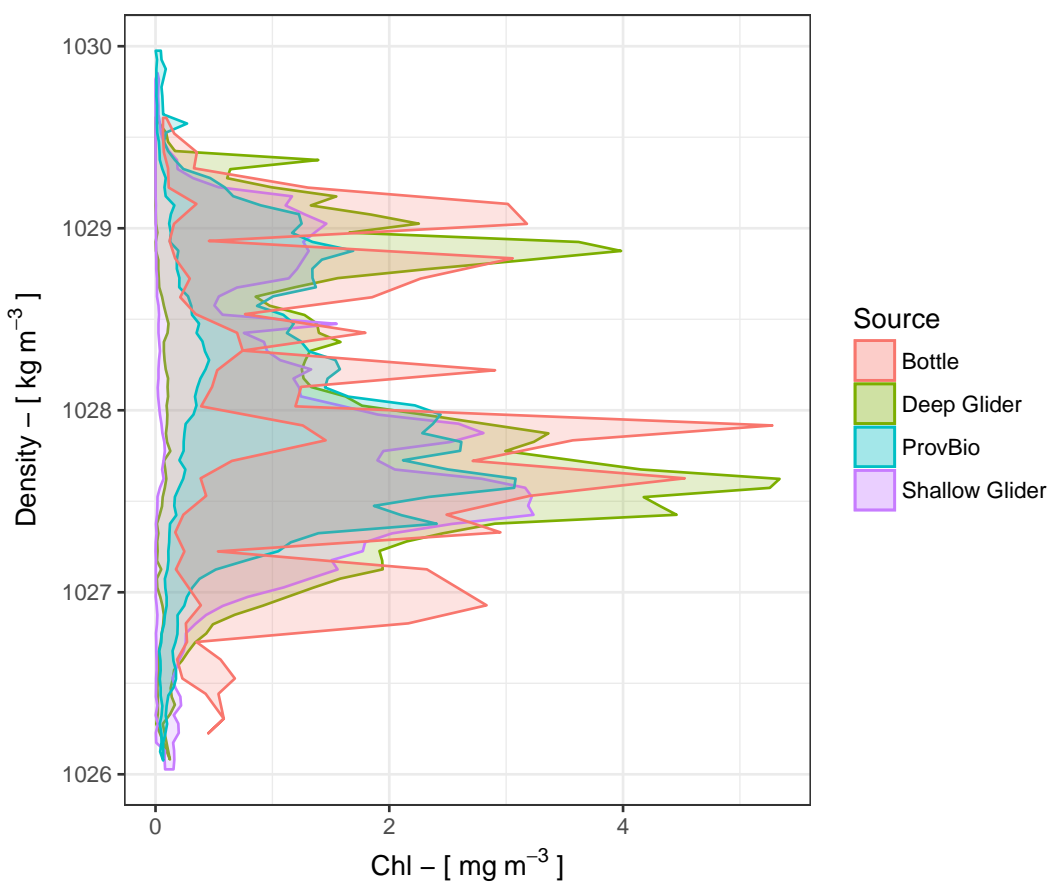

Fig. 2 Density distribution of Chl retrieved by the different sampling platforms. Shaded area depicts the range between Chl extrema evaluated for the different data sources within 0.05 $\mathrm{kg} \mathrm{m}^{-3}$ density bins $\left(0.1 \mathrm{~kg} \mathrm{~m}^{-3}\right.$ for bottle samples). It deserves to be noticed that samples are collected in the same period and area but are not perfectly co-located both in time and space. Sampled scales also varies between sources.

\subsection{PAR vertical distribution}

The depth distribution of photosynthetically active radiation (PAR, $\mu \mathrm{E} \mathrm{m}^{-2} \mathrm{~s}^{-1}$ ) is expressed as a bimodal attenuation function (Zielinski et al, 2002):

$$
\begin{aligned}
P A R(z) & =\operatorname{PAR}(0) \cdot\left(p_{s} \cdot e^{-\int_{0}^{z} k_{s}\left(z^{\prime}\right) d z^{\prime}}+\left(1-p_{s}\right) \cdot e^{-\int_{0}^{z} k_{l}\left(z^{\prime}\right) d z^{\prime}}\right), \\
k_{s}(z) & =k_{s, s w}+k_{s, C h l} \cdot \operatorname{Chl}(z), \\
k_{l}(z) & =k_{l, s w}+k_{l, C h l} \cdot \operatorname{Chl}(z),
\end{aligned}
$$


with short-wave fraction $p_{s}=0.806$; sea-water attenuation coefficient for short and long-waves component $k_{s, s w}=0.05295 \mathrm{~m}^{-1}$ and $k_{l, s w}=3.18910^{-6} \mathrm{~m}^{-1}$, respectively; short and long wave chlorophyll specific attenuation $k_{s, C h l}=0.03328$ $\mathrm{m}^{2}(\mathrm{mg} \mathrm{Chl})^{-1}$ and $k_{l, C h l}=7.23 \mathrm{~m}^{2}(\mathrm{mg} \mathrm{Chl})^{-1}$, respectively. These five parameters were calibrated to reproduce the PAR profiles measured by the Prov-bio float using the R FME package (Soetaert and Petzoldt, 2010). More details are provided in the Appendix. $C h l(z)$ is provided in situ from glider fluorescence data (and float fluorescence sensor for the model calibration phase). The surface PAR value was obtained from the ECMWF ERA-interim 6-hourly dataset. Such a surface PAR dataset was then resampled in time and interpolated in space to match the temporal and spatial framework of the glider.

\subsection{Primary Production}

Primary production has been estimated through a bio-optical method (Morel and Andrè, 1991; Antoine et al, 1996). In particular, (4) was applied for instantaneous synoptic estimations of primary production rates:

$$
P P(z, t)=12 C h l(z, t) a^{*}(z, t) P A R(z, t) \phi_{\mu}(z, t)
$$

where $C h l$ is the measured concentration of Chlorophyll-a in $\mathrm{g} \mathrm{Chlm}^{-3} ; a^{*}$ is the specific absorption of phytoplankton, expressed as $\mathrm{m}^{2}(\mathrm{~g} \mathrm{Chl})^{-1}$; PAR is the irradiance expressed as (molquanta) $\mathrm{m}^{-2} \mathrm{~s}^{-1}$ and $\phi_{\mu}$ represents the transformation efficiency expressed as mol C (molquanta) $)^{-1}$. The PP instantaneous rates are converted from mol $\mathrm{C}$ to $\mathrm{g} \mathrm{C}$ by using the carbon molar weight, which is 12 $\mathrm{g} \mathrm{C}(\mathrm{mol} \mathrm{C})^{-1}$.

In our specific application PP was computed as function of depth (z) and time (t). Space(y) was used for convenience as frame of reference in plotted glider sections instead of time $(\mathrm{t})$. We neglected the wavelengths $(\lambda)$ discretization (Morel and Andrè, 1991; Antoine et al, 1996; Hemsley et al, 2015). As reported by Hemsley et al (2015), this can imply an underestimation of depth-integrated PP values up to $50 \%$ in respect to the use of discretized wavelengths. Nevertheless, Zielinski et al (2002) showed that the bimodal approach to reconstruct the underwater light field (used in the present study to reconstruct the PAR profile) is comparable to the multiband approach by Antoine et al (1996) in terms of ability to model the DCM concentration. Furthermore, and most important, the bimodal model for PAR showed the best fitting with observed vertical PAR (see appendix).

This instantaneous PP $\left(\mathrm{g} \mathrm{Cm}^{-3} \mathrm{~s}^{-1}\right)$ can be integrated in time and depth to obtain PP estimations dimensionally comparable with satellite based estimates $\left(\mathrm{g} \mathrm{C} \mathrm{m}^{-2} \mathrm{~d}^{-1}\right)$.

For $a^{*}$ we used the standard value of $0.01 \mathrm{~m}^{2}(\mathrm{~g} \mathrm{Chl})^{-1}$ as proposed by Morel and Andrè (1991), which was also used in a glider based study of the PP in the North Atlantic (Hemsley et al, 2015). Concerning $\phi_{\mu}$, we used the formulation reported by Antoine et al (1996)

$$
\phi_{\mu}=\phi_{\mu, \max } f(x),
$$

where the transformation yield is equal to the maximum yield $\phi_{\mu, \max }$ (here set equal to $0.06 \mathrm{~mol} \mathrm{C} / \mathrm{mol}$ quanta scaled by the function $f(x)$ (defined within 0 and 
1 ), where $x=P U R / K P U R$ and $f(x)=\frac{1-e^{-x}}{x} e^{-\beta x}$. Here, PUR is the Photosynthetically Usable Radiance while $K P U R$ is a scaling irradiance. $\beta$ is a dimensionless parameter for photoinhibition set to 0.01 (Hemsley et al, 2015). KPUR is set as function of in situ temperature, also collected by the glider, following the expression (e.g. Hemsley et al, 2015):

$$
\operatorname{KPUR}(T)=\operatorname{KPUR}\left(20^{\circ}\right) 1.065^{\left(T-20^{\circ}\right)}
$$

We performed two separate computations of depth resolved PP: the first PP estimation was computed in the instrument sampling space to provide a picture of the actual instantaneous production in the glider space and time frame (PPg hereafter). In order to get such ephemeral rate comparable with a more conservative quantity as the Apparent Oxygen Utilization (AOU), we also computed a noon Primary Production (PPn) i.e. assuming that the glider sampled instantaneously at noon of each day. So in PPn computation the time (t) dependency is substituted by a space (y) dependency. PPn calculation allows to relate a non conservative quantity, as Primary Production is, with other variables such as the AOU shaped by the biological history of the water mass under investigation. The relation between these two quantities provides precious information on the underlying biological processes.

\section{Results}

\subsection{The AlborEx context}

The AlborEx experiment was carried out in the Eastern Alboran Sea, specifically at the edge of an anticyclonic mesoscale eddy (Pascual et al, 2017). This eddy was a persistent feature in the period immediately preceding AlborEx and during the sampling as well, as shown by time series of satellite single swath images in visible and infrared bands (Fig.3). The eddy shaped (advecting it and/or locally contributing to its production) the chlorophyll footprint in an anticyclonic curvature. This curvature, also visible in SST, is a characteristic imprint of a meandering jet of cold Atlantic waters (e.g. Tintoré et al (1988), Oguz et al (2014)) that enter the Alboran Sea through the Gibraltar Strait. These Atlantic waters (AW), circulated along the eddy periphery and entrained into Mediterranean waters (MW) in the north-eastern side of the mesoscale eddy, forming sharp gradients visible in SST. During the AlborEx experiment, gliders intercepted one of these filaments and unveiled remarkable chlorophyll subduction underneath them (Fig. 4), subduction reaching and exceeding $100 \mathrm{~m}$ depth in terms of chlorophyll signature.

\subsection{Hydrography and deep chlorophyll maximum}

In the following, the SG sampling is considered in virtue of its finer spatial resolution reaching sub-mesoscale. AlborEx gliders sampled a sharp front in salinity at the confluence of Atlantic and Mediterranean waters (Fig. 5a). Such salinity gradient was the main responsible for a lateral density gradient of $\Delta \rho \sim 1 \mathrm{~kg} \mathrm{~m}^{-3}$ in about $10 \mathrm{~km}$ (Fig. 5b). Subsurface chlorophyll patches within the DCM (Fig. 5c) 

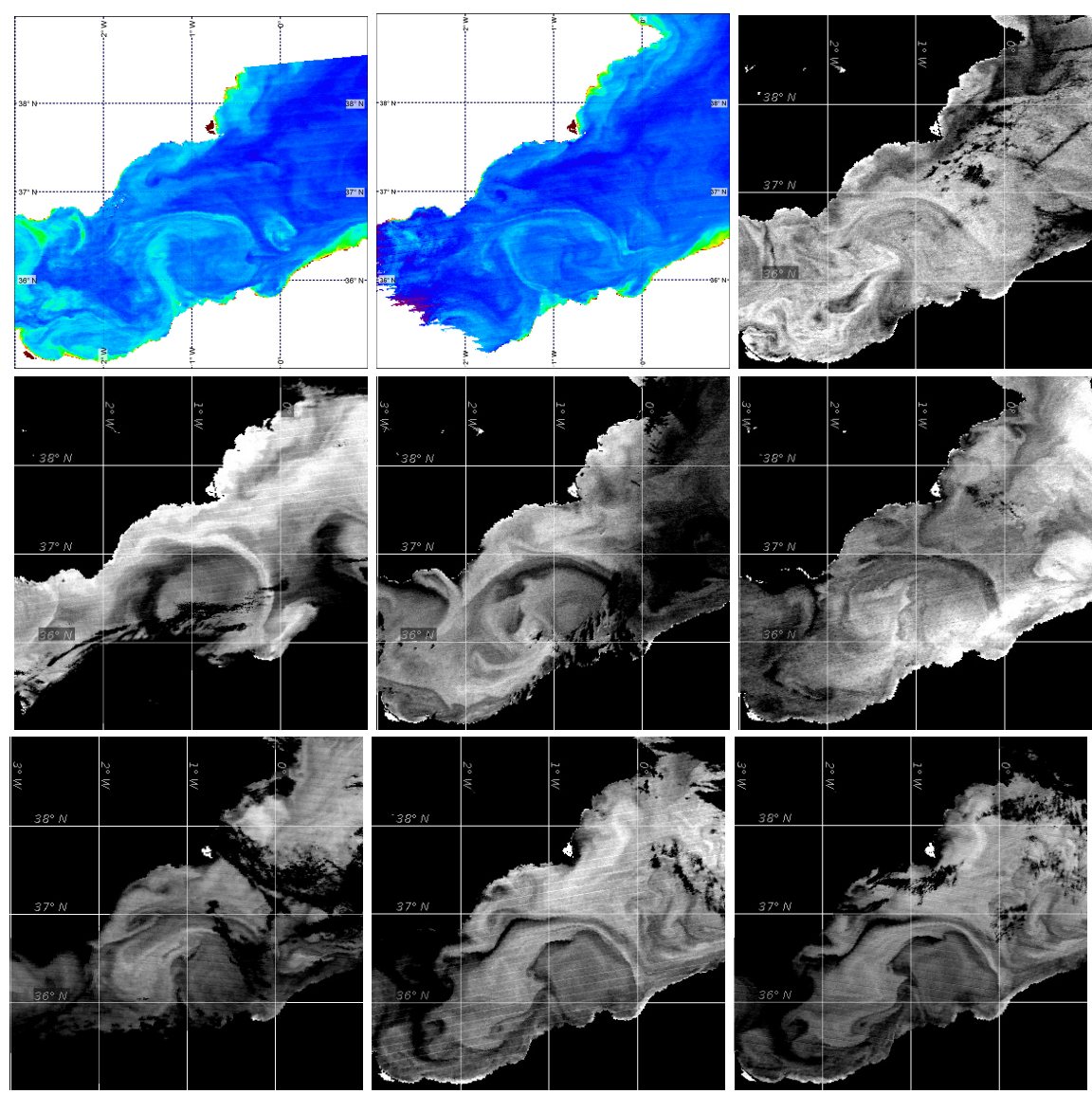

Fig. 3 Series of satellite data (MODIS Level-2 single swaths). First image (top left) is for May 3, 2014 and last image for May 30 (bottom right). Colored images are ocean color, black-white are SST. Left to right and top to bottom, days of May 2014: 3, 5, 12, 18, 21, 25, 27, 29, 30. The glider sampled the frontal/eddy system between May 25 and 30 (last four images).

reached extremely high concentration (up to $3 \mathrm{mg} \mathrm{m}^{-3}$ for $\mathrm{SG}$ and $5 \mathrm{mg} \mathrm{m}^{-3}$ for DG and bottles, see Sect. 2.3) in respect to usual values for the Mediterranean DCM, even in such strong frontal areas (cf. Moran et al, 2001, with maximum of $\left.1.4 \mathrm{mg} \mathrm{m}^{-3}\right)$.

The Chl distribution is strongly heterogeneous in both the horizontal and the vertical dimension, suggesting strong frontal dynamics. Such patchiness can be related to the static stratification of the water described by the buoyancy frequency. Chlorophyll contours of $0.5 \mathrm{mg} \mathrm{m}^{-3}$ (Fig. 5d) match quite well with the relative lows of buoyancy frequency within the 30-60 m layer. In the fresh side of the front, Chl patches were found across the mixed layer limit, defined with a density threshold of $0.03 \mathrm{~kg} \mathrm{~m}^{-3}$ (de Boyer Montégut et al, 2004) with respect to a sub-surface reference level at $20 \mathrm{~m}$ (shallowest depth of glider sampling). In contrast, in the high-salinity side of the front, deep patches $(>60 \mathrm{~m})$ are located well below the area of high stratification (high values of $N^{2}$ ). Large values of Chl are found concurrently with isopycnal doming on the fresh side of the front and 


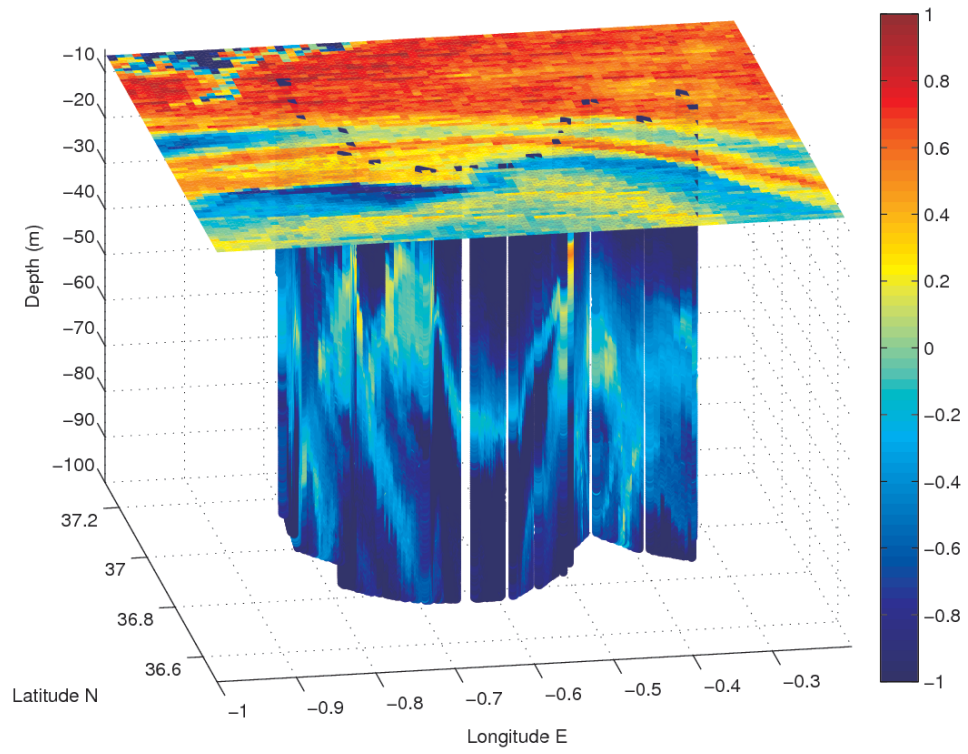

Fig. 4 SST field (the horizontal plane on the top) superimposed on the vertical Chl distribution detected by the SG glider. Units for SST are Celsius degrees ${ }^{\circ} \mathrm{C}$ from which have been subtracted $-19{ }^{\circ} \mathrm{C}$ (in order to keep a single palette and colorbar) and $\log (\mathrm{Chl})$ in $\mathrm{mg} \mathrm{m}^{-3}$ for Chl.

within the interface (i.e. not in the core of the fresh waters). Such doming suggest the presence of upwelling/downwelling motion along isopycnals, also confirmed by disruptions in stratification.

The vertical distribution of Chl seems primarily determined by the density of water masses and secondarily by the vertical motion of such water masses. Indeed, water mass density instead of depth allows to distinguish different "populations" (not in biological sense) of planktonic biomass distribution (Fig. 6). The relation with potential density discerns three different peaks respectively for MW, AW and interface waters. On the contrary, AW and MW peaks are partly superimposed in the Chl-depth relation.

\subsection{Primary Production}

Estimated primary production rates, both in the glider sampling frame (PPg, Fig.7a) and in the synoptic frame at noon (PPn, Fig.7b) are shown. It is evident, as expected, that production patches are coincident with patches of high Chl concentration, in particular for the shallowest ones upwelled along isopycnals. Instantaneous values per unit of volume (converted in daily rates for convenience of representation) reach $0.5 \mathrm{~g} \mathrm{C} \mathrm{m}^{-3} \mathrm{~d}^{-1}$ for $\mathrm{PPg}$ and exceeds $0.8 \mathrm{gC} \mathrm{m}^{-3} \mathrm{~d}^{-1}$ for PPn.

Integrated quantities over the euphotic layer (defined as the depth at which PAR equals $1 \%$ of the surface value) for PPg estimates are reported in Tab. 1, together with averaged values for the main satellite PP products (averaged along the glider track from the 8-days level-3 product covering the sampling period, please 

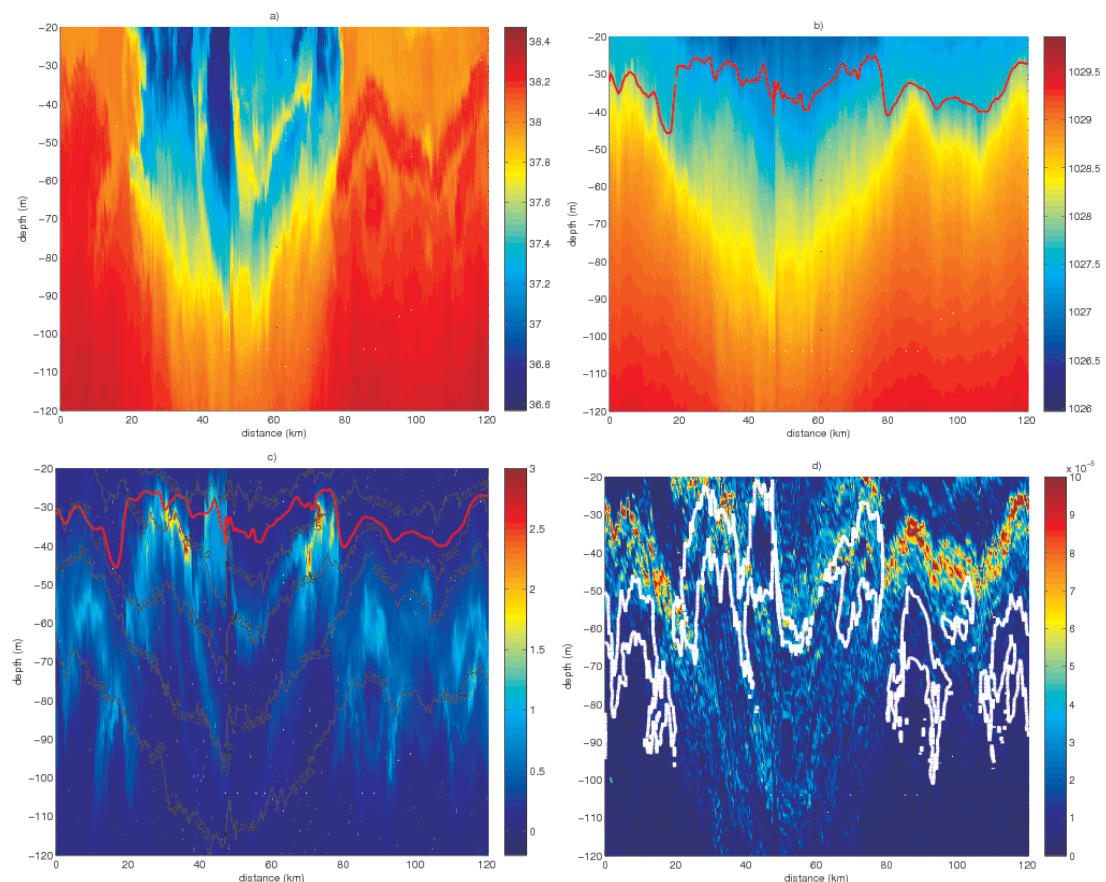

Fig. 5 a) Salinity; b) Density $\rho, \mathrm{kg} / \mathrm{m}^{3}$, with MLD superimposed (red curve); c) Chlorophyll, $\mathrm{mg} \mathrm{m}{ }^{-3}$, with superimposed isopycnals (grey curves); d) buoyancy frequency $N^{2}$ with the $\mathrm{Chl}=0.5 \mathrm{mg} \mathrm{m}^{-3}$ contour superimposed in white. Cross-front sections correspond to the coastal glider (see Fig. 1 for trajectory).
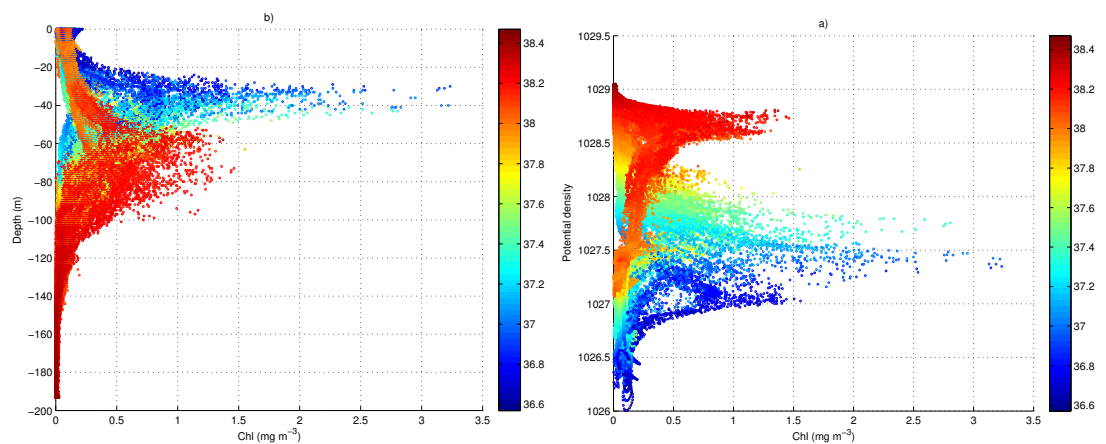

Fig. 6 Scatterplot of Chl $\left(\mathrm{mg} / \mathrm{m}^{3}\right)$ vs a) depth $(\mathrm{m})$; b) potential density $\left(\mathrm{kg} / \mathrm{m}^{3}\right)$. For both panels, color is salinity. It is evident how chlorophyll peaks are better discerned in terms of potential density.

see http://www.science.oregonstate.edu/ocean.productivity/for satellite products documentation). It is evident that satellite products tend to largely underestimate $\mathrm{Chl}$ and $\mathrm{PP}$ values in frontal zones during the stratification period, i.e. when the light-limited production mainly takes place within the DCM and can be boosted at depth by uplifting mechanisms without strong surface manifestation. 

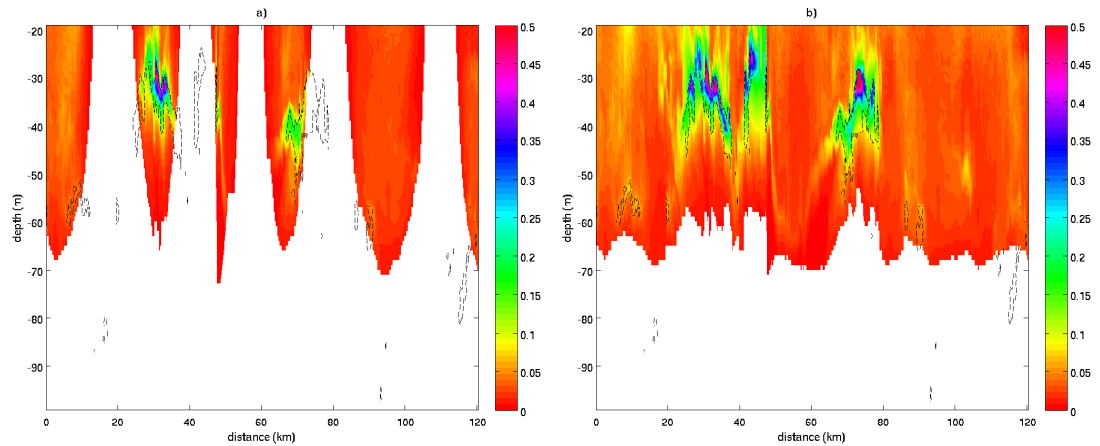

Fig. 7 Primary production estimates a) in the sampling space (PPg) and b) synoptic estimates at noon (PPn). In panel b) the x-axis is expressed in terms of "profiles" instead of "time" accordingly to the synoptic assumption done for PPn computations. Units are $\mathrm{g} \mathrm{C}^{-3} \mathrm{~d}^{-1}$. Black dashed lines indicate $1 \mathrm{mg} \mathrm{m}^{-3} \mathrm{Chl}$ contour.

Table 1 Vertically integrated primary production averaged along the glider track, considering present estimates (PPg) and three of the main products for PP freely distributed. Units are $\mathrm{g} \mathrm{C} \mathrm{m}^{-2} \mathrm{~d}^{-1}$

\begin{tabular}{llll}
\hline PPg & sat VGPM & sat CBPM & sat Eppley \\
\hline 1.32 & 0.68 & 0.32 & 0.46 \\
\hline
\end{tabular}

Such value, we remind strictly related to this particular front and sampling, on one hand exceeds in situ estimations of integrated production during spring period in high trophic areas of Mediterranean, as for instance the Gulf of Lyon (Lefevre et al, 1997, reporting integrated maxima of $\left.0.5 \mathrm{~g} \mathrm{C} \mathrm{m}^{-2} \mathrm{~d}^{-1}\right)$. On the other hand, it is close to the largest estimations we found for integrated production during the stratification period for the NW Mediterranean (Estrada, 1996, with about 2 $\left.\mathrm{g} \mathrm{C} \mathrm{m}^{-2} \mathrm{~d}^{-1}\right)$ but retrieved in October, at the end of the stratification season.

\subsection{Apparent Oxygen Utilization}

Apparent Oxygen Utilization (AOU) helps in understanding the processes underlying the observed $\mathrm{Chl}$ distribution and PP. AOU is computed as the difference between the theoretical (i.e. at saturation) and observed oxygen concentrations (expressed in umol/l). It can be considered as a buffer diagnostic, which integrates in time the biogeochemical terms of oxygen dynamics in aquatic environments. Large negative values of AOU were found during the glider sampling (Fig. 8) from the surface down to the oxycline (here defined as the depth where the oxygen vertical gradient is the largest). In biologically active layers (such as the DCM and the mixed layer), such negative values indicate that oxygen production rates exceed consumption rates. The change of sign, negative to positive from surface to bottom, happens concurrently with centers of biological production located in the DCM, with steeper vertical AOU gradient in the AW (at the interface), and smoother gradient for the DCM located in the bulk of the MW (Fig. 8).

A negative linear relationship is observed between AOU and $\log (P P n)$ (Fig. 9, scat- 
ter plot restricted to waters with large phytoplankton content, Chl $>0.5 \mathrm{mg} \mathrm{m}^{-3}$ ), supporting the validity of PP estimates. The slope of this relationship is steeper for mixed waters $\left(1027<\rho<1028.3 \mathrm{~kg} / \mathrm{m}^{3}\right)$, where the largest production occurs (Fig. 8a), than for Mediterranean waters $\left(\rho>1028.3 \mathrm{~kg} / \mathrm{m}^{3}\right)$. The bulk of Atlantic waters $\left(\rho<1027 \mathrm{~kg} / \mathrm{m}^{3}\right)$ show an inverse relationship between AOU and $\log (\mathrm{PPn})$. The milder slope in MW, where negative AOU values are associated with poorly productive layers, suggests the subduction of formerly productive waters to lowlight layers on the Mediterranean side of the front, still preserving negative AOU values (i.e. oxygen supersaturation).

Figure $9 \mathrm{~b}$ depicts the same relationship but colored as function of the backscattering/Chl ratio (Optical Community Index, Cetinić et al, 2015). Large values of this ratio indicate a larger probability for the prevalence of microphytoplankton and diatoms dominated communities, while small values the prevalence of pico and nano-phytoplankton. It is interesting to note that such ratio does not change between AW and MW, while it assumes large values (for the mixed waters with a density $\rho$ of about $1027.5 \mathrm{~kg} / \mathrm{m}^{3}$, cfr. with panel a) in coincidence with the largest PP values. Also, the lowest values of the Optical Community Index are found along the same cloud of points related to the mixed waters concurrently with low PP values. Accordingly to the findings of Ruiz et al. (submitted), the latter patches are being subducted due to submesoscale frontal dynamics along the interface between two water masses. Consequently, they are likely subject to acclimation (physiological and/or at community level) to the new light conditions.

These observations suggest that the physical environment, in these particular conditions, is able to shape the phytoplankton community at the sub-mesoscale $(1-10 \mathrm{~km})$ and in coincidence with the frontal region, in agreement with recent observations reporting the sub-mesoscale spatial structuring of phytoplankton at population level (Mousing et al, 2016).
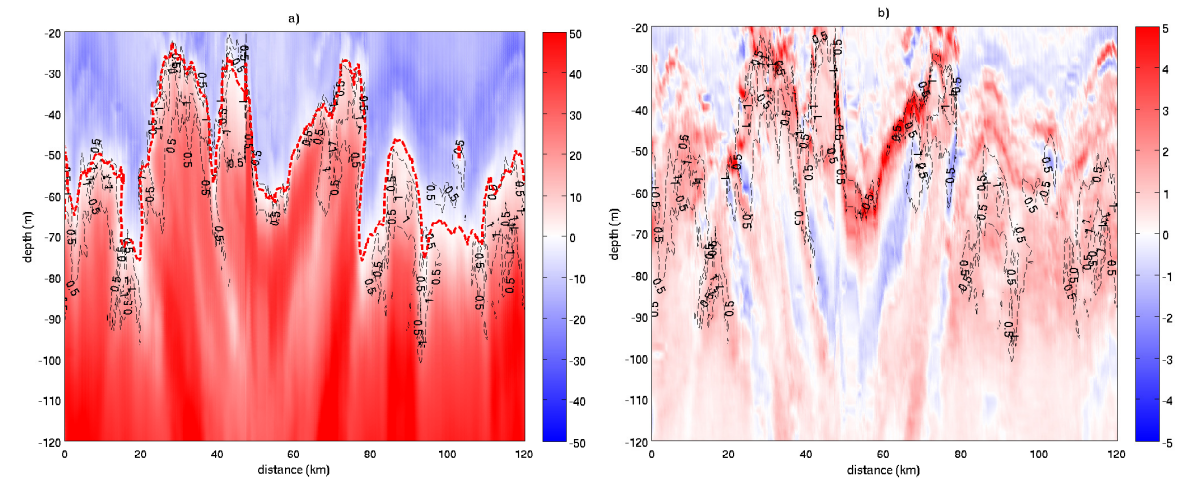

Fig. 8 a) Apparent Oxygen Utilization (AOU, umol/l) distribution in the top $120 \mathrm{~m}$. Thick red line is the zero AOU curve. b) AOU vertical gradient. Black dotted (labeled) lines on both panels corresponds to iso-contours of $\mathrm{PPn}$. 

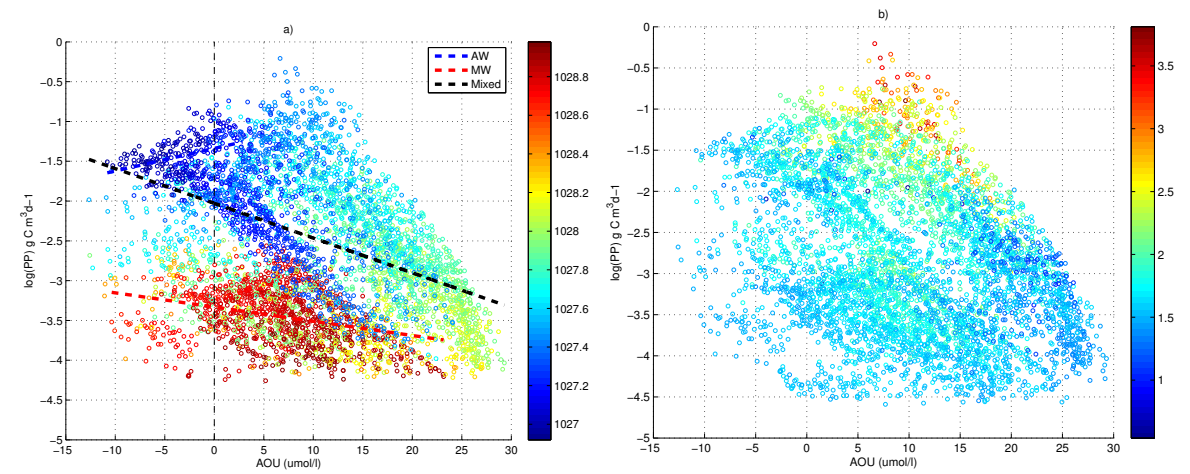

Fig. 9 Scatterplot of AOU vs $\log (\mathrm{PPn})$ colored as function of a) density $\left(\mathrm{kg} / \mathrm{m}^{3}\right)$; b) Backscattering/Chl ratio (digital counts) 


\section{Discussion and Conclusions}

The present study uses a set of high resolution bio-physical glider observations (salinity, temperature, oxygen, fluorescence, turbidity) to investigate the impact of frontal processes on the primary production associated to a Deep Chlorophyll Maximum. The primary production is estimated using a methodological approach similar to that presented by Hemsley et al (2015) in the North Atlantic. The two main variations of this method here are the estimation of PAR radiation, which is based on synchronous PAR observations performed through Argo floats, and the use of a single irradiance value for PP algorithm (not discretized in $\lambda$ bands).

DCM is known to be an ubiquitous feature that, in temperate regions, onsets after seasonal thermal stratification and consequent nutrient depletion of the top mixed layer (Cullen, 1982). This simple theoretical frame for DCM formation and functioning is complicated by presence and action of ubiquitous mesoscale and sub-mesoscale structures. It was largely shown (cfr. McGillicuddy, 2016; Mahadevan, 2016, for two reviews about impacts of mesoscale and submesoscale dynamics, respectively) that (sub-)mesoscale features impact the biology through several mechanisms. Nutrient uplift of nutrients; subduction of organic matter; dynamical re-stratification (Taylor and Ferrari, 2011a; Mahadevan et al, 2012) are some of the main processes impacting biogeochemistry and consequently biology at such scales. Very little can be found in literature about the role of such dynamical features in the modulation of the biological activity during stratification and DCM onset. During stratification, while the ML is nutrient-limited the DCM is substantially light-limited. At such low light conditions, photoacclimation processes may occur (Lazzara et al, 1996; Mignot et al, 2014), determining an increase of the Chl content in cells and a possible decoupling of the biomass peak from the DCM (Mignot et al, 2014). Given that the PAR reaching the DCM is usually between 1 and $10 \%$ of the incident radiation at surface (Siswanto et al, 2005), it could be assumed a weak contribution of DCM to total annual production. In this case, the error in satellite-based production estimates, associated with the inability of space-borne sensors to see the full euphotic water column and with the consequential need for approximations (namely uniform or gaussian distributions of Chl along the water column), could be actually negligible.

This picture can be drastically modified by the intervention of (sub-)mesoscale dynamics, as observed in the present study. Biomass and production estimates obtained in-situ during AlborEx are unusually high for such period of the year in comparison to satellite-based estimations, notwithstanding the prudent approach we adopted in estimating primary production. The largest production is observed concurrently with shallower phytoplankton patches, initially belonging to the DCM level and therefore substantially light-limited, up-lifted to euphotic depths by mechanisms related to mesoscale and to frontal (ageostrophic) dynamics (Ruiz et al, 2017). The bio-optical estimations of large primary production levels $\left(1.3 \mathrm{~g} \mathrm{C} \mathrm{m}^{2} \mathrm{~d}^{-1}\right)$ are supported by negative AOU values within the ML and negative AOU/production relationship, having a different slope for the different water masses. The steepest slope is found for mixed waters, which is indicative of a tighter coupling between production and AOU, i.e. a more intense biological activity.

It is quite instructive to look upon the vertical/pycnal distribution of Chl through the lens of the hysteresis theory for DCM presented by Navarro and Ruiz 
(2013). The Authors observed worldwide that the vertical position of the DCM is better explained in terms of density, following the seasonal history of water masses, than in terms of instantaneous physico-chemical, depth-related diagnostics (eg. mixed layer depth, nutricline). In a few words, the density at which the DCM forms during stratified conditions corresponds to the density of the previous winter mixed layer bloom. The authors suggest that, during winter blooms, the planktonic assemblage is tailored around the density conditions of the winter mixed layer, and that this preference persists along the seasons and impress upon the vertical position of the DCM during the stratified period.

Here, two water masses of distinct origins encounter forming a sharp front. According to the hysteresis paradigm, they carry distinct populations, tailored to distinct density levels, which is in agreement with the distribution pictured on Fig. 6b. In general, the uplifting of the AW DCM isopycnal in euphotic depths triggers high primary production. But the highest PP occurs in mixed waters, i.e. on the Atlantic, fresher, side of the front. Here, a change in the planktonic assemblage (and/or a physiologic adjustment) is suggested by the Optical Community Index (Fig. 9b). It could be speculated that favorable conditions (light and nutrients) are met in a new density niche emerging at the front, which the dominant species of the Med and Atlantic assemblages might not be used to exploit. This would lead to a reorganization of the planktonic web structure (Mousing et al, 2016) in which a new player is able to grow, unchallenged on these short time-frame.

Clearly, the preceding paragraph is highly speculative at this point. Our primary statement is that a sub-surface increase in the DCM production, substantially unspotted from space, is caused by strong vertical motions at the front (Pascual et al, 2017). This is directly supported by the presented results and does not require any assumption regarding the reason behind the different DCM positions in Atlantic and Mediterranean waters. Beyond that, our observations also suggest that frontal dynamics might affect biogeochemical processes through strictly biological mechanisms and call for further investigations. Such efforts would have to be supported by an AlborEx-like cruise but complemented with in-situ production estimates and microscopic analyses to characterize planktonic populations.

The high production rates estimated along the frontal area, also previously reported in the literature for frontal regions of the Alboran sea (Videau et al, 1994; Moran et al, 2001, with maxima of $\sim 2 \mathrm{~g} \mathrm{C} \mathrm{m}^{2} \mathrm{~d}^{-1}$ ), may be relevant to better understand the functioning of the Mediterranean ecosystem. It is still unclear, for instance, how the Mediterranean can sustain a large yield of fish catches (and thus a large secondary production) in front of a relatively low primary production (Estrada, 1996). Could the chronic underestimation of the production related to the DCM explain this issue? On the one hand, it could be argued that such large values of production could be found only locally in the vicinity of intense fronts. On the other hand, the entire southern part of the Western Mediterranean (the Algerian Basin) is largely populated by mesoscale AW eddies and therefore frontal structures at the periphery of these eddies, such as the one intercepted in our study, may be ubiquitous in the area. The application of the present glider-based methodology for PP estimation (properly calibrated) to a larger Mediterranean dataset covering the eddy field of the Algerian Basin, during DCM conditions, would substantially help to reply to the above question, still unresolved. 
Acknowledgements This work has been partly funded by the Jerico-TNA program, under the project named FRIPP (FRontal Dynamics Influencing Primary Production), and by the Italian Flagship Project RITMARE.AlborEx experiment was financed by the Perseus project, Funded by the EU under FP7 Theme Oceans of Tomorrow OCEAN.2011-3 Grant Agreement No. 287600. Arthur Capet is a FNRS researcher under the FNRS BENTHOX project (Convention T.1009.15).

Authors would also like to thank Dr. Stefania Sparnocchia for her precious support as responsible for the JERICO-TNA program; Dr. Marc Toner Tomàs who has efficiently piloted the gliders; Dr. Charles Troupin for providing relevant technical information; Dr. Victoria Hemsley for her precious suggestions about PP algorithm; Dr. David Roque by helping in bottle data processing.

\section{A Calibration of the optical model}

The pragmatic objective of this section is to calibrate, on the basis of the Prov-Bio optical data (Sect. 2.2), an optical model suited to reconstruct the PAR conditions along the AlborEx coastal glider (SG) transect. For this specific objective, only the profiles obtained between the 26 st of May and the 7th of June were considered, when the Prov-Bio path was close to the AlborEx front.
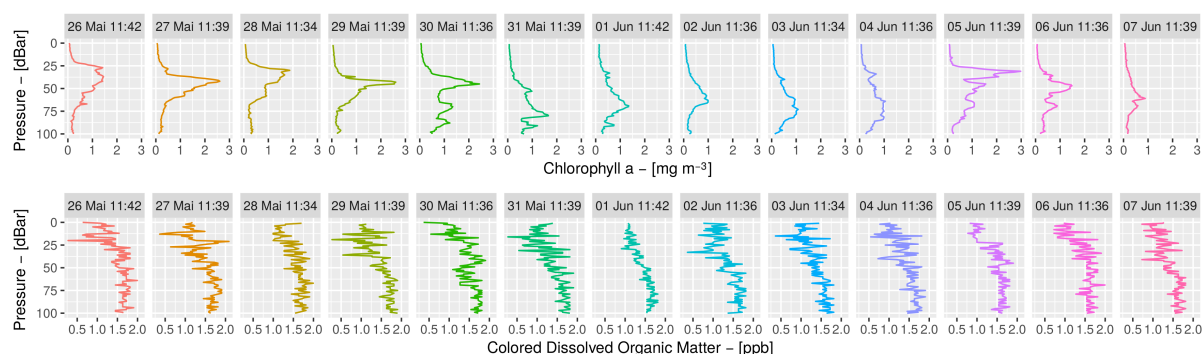

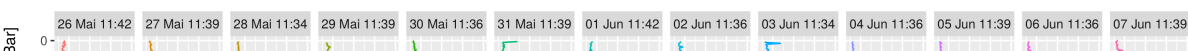

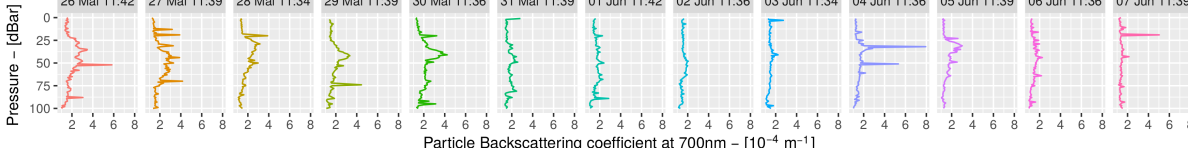

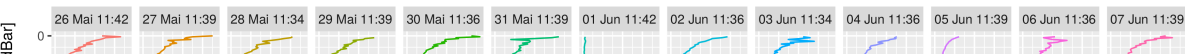

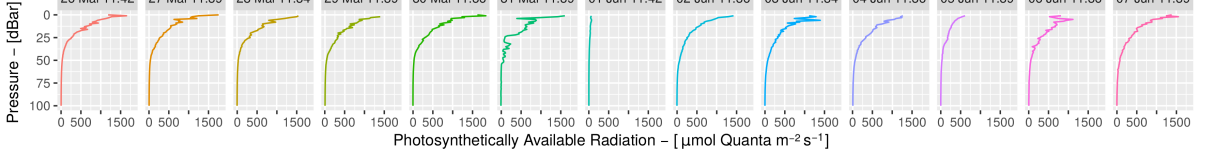

Fig. 10 Optical parameters recorded by the Prov-Bio floats near the AlborEx front.

Several candidate optical models were tested, considering a single bandwidth with Chl and CDOM attenuation $\left(P A R_{1}\right)$, or two bandwiths (Zielinski et al, 2002) with attenuation from 


$$
\begin{aligned}
& P A R_{1}\left\{\begin{array}{ll}
P A R(z) & =P A R(0) \cdot e^{-\int_{0}^{z} k\left(z^{\prime}\right) d z^{\prime}} \\
\text { with } k(z) & =k_{0}+k_{C h l} \cdot C h l(z)+k_{C D M} \cdot C D M(z)
\end{array}\right] \\
& P A R_{2}\left\{\begin{array}{ll}
P A R(z) & =P A R(0) \cdot\left[p_{s} \cdot e^{-\int_{0}^{z} k_{s}\left(z^{\prime}\right) d z^{\prime}}+\left(1-p_{s}\right) \cdot e^{-\int_{0}^{z} k_{l}\left(z^{\prime}\right) d z^{\prime}}\right] \\
k_{s}(z) & =k_{s, 0}+k_{s, C h l} \cdot C h l(z) \\
k_{l}(z) & =k_{l, 0}+k_{l, C h l} \cdot C h l(z)
\end{array}\right] \\
& P A R_{3} \begin{cases}P A R(z) & =P A R(0) \cdot\left[p_{s} \cdot e^{-\int_{0}^{z} k_{s}\left(z^{\prime}\right) d z^{\prime}}+\left(1-p_{s}\right) \cdot e^{-\int_{0}^{z} k_{l}\left(z^{\prime}\right) d z^{\prime}}\right. \\
k_{s}(z) & =k_{s, 0}+k_{s, C h l} \cdot C h l(z)+k_{s, C D M} \cdot C D M(z) \\
k_{l}(z) & =k_{l, 0}+k_{l, C h l} \cdot C h l(z)+k_{l, C D M} \cdot C D M(z)\end{cases}
\end{aligned}
$$

For the sake of simplicity, and since all profiles were taken at the same hour of the day in a 12-day interval, the incoming surface radiation was considered to be identical for all profiles and was tuned as a single parameter. Only two profiles were excluded for the calibration (corresponding respectively to the 1st and 5th of June) as they presented obviously affected incoming surface radiation, for instance due to cloud cover (Fig. 10).

The parameters of models $P A R_{1}, P A R_{2}$ and $P A R_{3}$ were calibrated to reproduce at best the corresponding Prov-Bio PAR profiles, when applied on the concurrent Chl and CDOM data. The skill associated with each model is given as the root of the PAR mean squared residuals evaluated for all the selected profiles (i.e., 11 profiles consisting of $\sim 215$ measurement each) and are provided in Table 2).

\begin{tabular}{ccc} 
PAR Model & Number of parameters & RMS \\
\hline$P A R_{1}$ & 4 & 42.77 \\
$P A R_{2}$ & 6 & 41.20 \\
$P A R_{3}$ & 8 & 41.23
\end{tabular}

Table 2 Number of parameters and model skill evaluated for the optical models.

The consideration of two band widths in models $P A R_{2}$ and $P A R_{3}$ enhances the model skills. The consideration of CDOM in $P A R_{3}$ does not appears beneficial in what regards the model skill, and poses an additional question in terms of parameter identifiability.

We finally retained model $P A R_{2}$, with parameters $P A R_{0}=1532 \mu \mathrm{E} \mathrm{m}^{-2} \mathrm{~s}^{-1} ; p_{s}=0.806$; $k_{s, s w}=5.29510^{-2} \mathrm{~m}^{-1} ; k_{l, s w}=3.18910^{-6} \mathrm{~m}^{-1} ; k_{s, C h l}=3.32810^{-2} \mathrm{~m}^{2} \mathrm{mg} \mathrm{Chl}{ }^{-1} ; k_{l, C h l}=$ $7.23 \mathrm{~m}^{2} \mathrm{mg} \mathrm{Chl}^{-1}$

The probability distribution around those values, as well as the dependencies between different parameter estimates, are depicted on Fig. 11 showing the distribution of parameter values retained in a Monte Carlo Markov Chain procedure (Soetaert and Petzoldt, 2010). The pairwise relationships between successful parameter sets indicate a strong correlation between the long-wave band attenuation coefficients for sea-water $\left(k_{l, s w}\right)$ and Chl $\left(k_{l, C h l}\right)$. In other terms, the good matching between simulated and observed PAR profiles is somewhat equivalent whether the long-wave band is attenuated by seawater or Chl. We retained the best parameter values indicated above, which gives a large weight to $\mathrm{Chl}$ for the long-wave attenuation, but we checked carefully that the PP estimates obtained from SG data were only marginally affected when using a parameter set in which long-band attenuation was driven by sea water.

The $P A R_{2}$ model provides a representation of the PAR profiles suitable for the next steps of this study (Fig. 12, with percentage residuals always below $50 \%$ and usually well below $25 \%$ in the upper $60 \mathrm{~m}$, a depth below which PAR is always lower than $5 \%$ of the surface incoming radiation.

As the model calibration was restricted to AlborEx Prov-Bio input data we do not pretend that our conclusions concerning the optical model suitability apply, for instance, to the entire 


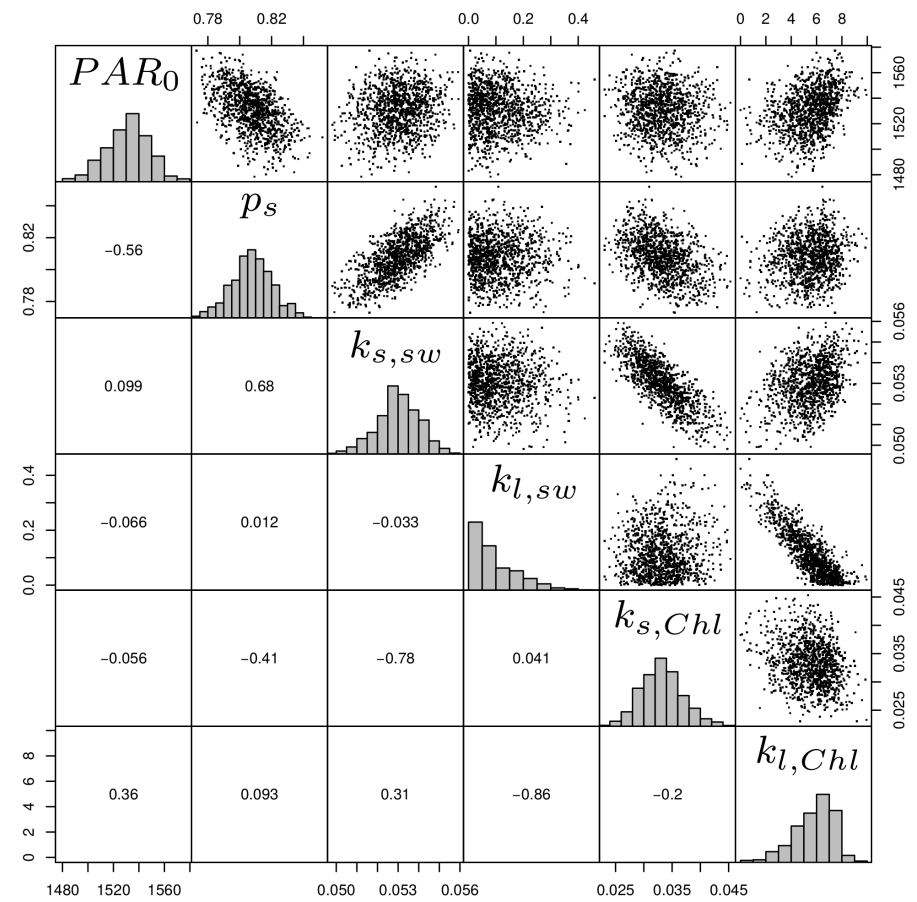

Fig. 11 Marginal parameter distributions (diagonal), pairwise relationship (upper panels) and correlation coefficients (lower panels) between parameters of the optical model $P A R_{2}$, obtained by applying a Markov Chain Monte Carlo procedure as described in (Soetaert and Petzoldt, 2010). Note the strong relationship between the calibrated sea water and chlorophyll attenuation coefficient, in particular for the long-wave light band.

Mediterranean Sea, over which the concentrations of optically relevant water constituents vary on ranges much larger than those encountered here.

\section{References}

Antoine D, Andrè J, Morel A (1996) Oceanic primary production : Ii. estimation at global scale from satellite (coastal zone color scanner) chlorophyll. Global Biogeochemical Cycles 10:57-69

Behrenfeld MJ (2010) Abandoning Sverdrup's Critical Depth Hypothesis on phytoplankton blooms. Ecology 91:977-989

Behrenfeld MJ, Falkowski PG (1997) Photosynthetic rates derived from satellite-based chlorophyll concentration. Limnology and Oceanography 42(1):1-20

de Boyer Montégut C, Madec G, Fischer AS, Lazar A, Iudicone D (2004) Mixed layer depth over the global ocean: An examination of profile data and a profile-based climatology. Journal of Geophysical Research: Oceans 109(C12):n/a-n/a, DOI 10.1029/2004JC002378, URL http: //dx.doi.org/10.1029/2004JC002378, c12003

Cetinić I, Perry MJ, D’Asaro E, Briggs N, Poulton N, Sieracki ME, Lee CM (2015) A simple optical index shows spatial and temporal heterogeneity in phytoplankton community composition during the 2008 north atlantic bloom experiment. Biogeosciences 12(7):2179-2194, DOI 10.5194/bg-12-2179-2015, URL http://www.biogeosciences.net/12/2179/2015/ 


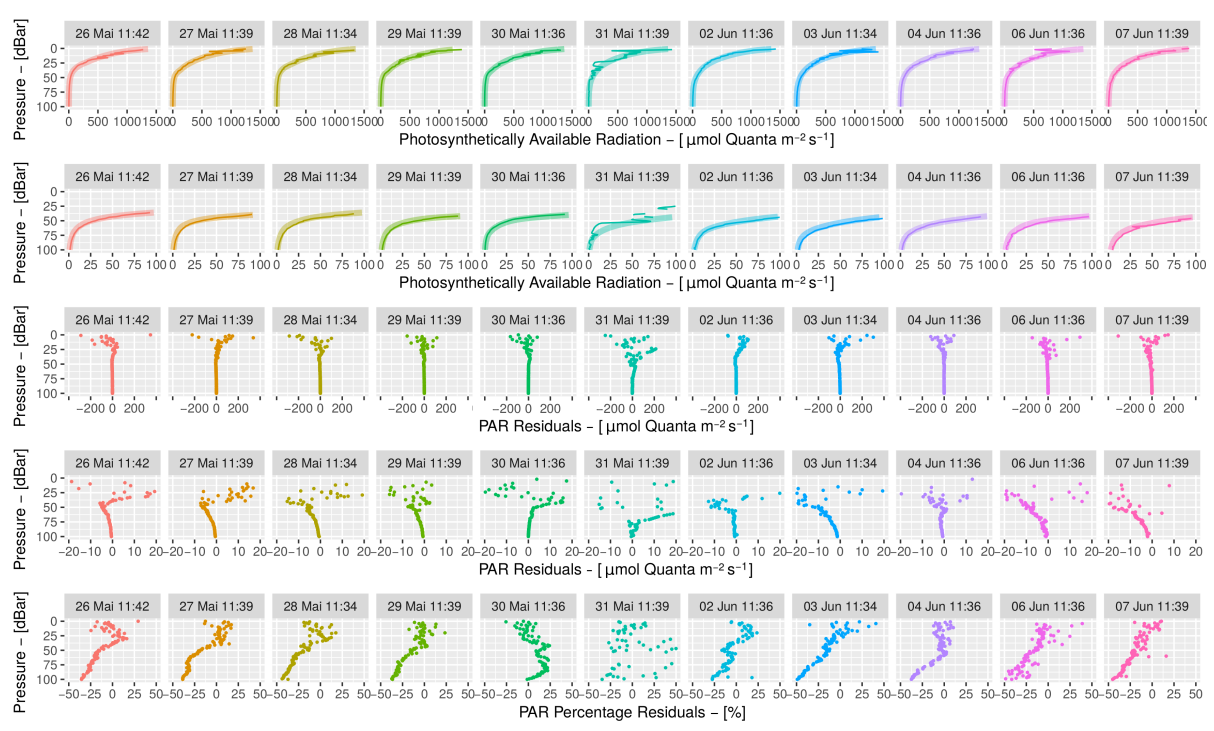

Fig. 12 PAR profiles reproduced by applying the $P A R_{2}$ function on Prov-Bio profiles. First and second rows presents (wide light line) modelled and (thin dark line) observed PAR profiles on different scales. Third and fourth rows present the corresponding residuals. The fifth row indicates the relative residuals, ie. $\frac{P A R_{\text {model }}-P A R_{\text {obs }}}{P A R_{o b s}} .100$

Chiswell SM (2011) Annual cycles and spring blooms in phytoplankton: Don't abandon sverdrup completely. Marine Ecology Progress Series 443:39-50

Chiswell SM, Calil PH, Boyd PW (2015) Spring blooms and annual cycles of phytoplankton: a unified perspective. Journal of Plankton Research DOI 10. 1093/plankt/fbv021, URL http://plankt.oxfordjournals.org/content/early/2015/04/ 08/plankt.fbv021.abstract, http://plankt.oxfordjournals.org/content/early/2015/ 04/08/plankt.fbv021.full.pdf +html

Cullen J (1982) The deep chlorophyll maximum: comparing vertical profiles of chlorophyll a. Canadian Journal of Fisheries and Aquatic Sciences 39(5):791-803, URL https://www.scopus.com/inward/record.uri?eid=2-s2.0-0020369517\&partnerID= 40\&md5=48cddb15fba9964e0cb50004cb0d8e37, cited By 442

Delgado M, Latasa M, Estrada M (1992) Variability in the size-fractionated distribution of the phytoplankton across the catalan front of the north-west mediterranean. Journal of Plankton Research 14(5):753-771, DOI 10.1093/plankt/14.5.753, URL https://www.scopus.com/inward/record.uri?eid=2-s2.0-0027038493\&partnerID= 40\&md5=672ea91e91812dd41e89e51c6242c325, cited By 41

Estrada M (1996) Primary production in the northwestern mediterranean. Scientia Marina 60 (Suppl.2):55-64

Franks PJS (2014) Has Sverdrup's critical depth hypothesis been tested? Mixed layers vs. turbulent layers. ICES Journal of Marine Science: Journal du Conseil DOI 10.1093/icesjms/fsu175, URL http://icesjms.oxfordjournals.org/content/early/2014/ 10/17/icesjms.fsu175.abstract, http://icesjms.oxfordjournals.org/content/early/ 2014/10/17/icesjms.f su175.full.pdf+html

Garau B, Ruiz S, Zhang WG, Pascual A, Heslop E, Kerfoot J, Tintoré J (2011) Thermal lag correction on slocum ctd glider data. Journal of Atmospheric and Oceanic Technology 28(9):1065-1071

Hemsley VS, Smyth TJ, Martin AP, Frajka-Williams E, Thompson AF, Damerell G, Painter SC (2015) Estimating oceanic primary production using vertical irradiance and chlorophyll profiles from ocean gliders in the north atlantic. Environmental Science \& Technology 49(19):11,612-11,621, DOI 10.1021/acs.est.5b00608, URL http://dx.doi.org/10. 1021/acs.est.5b00608, pMID: 26301371, http://dx.doi.org/10.1021/acs.est.5b00608 
Hodges B, Rudnick D (2004) Simple models of steady deep maxima in chlorophyll and biomass. Deep Sea Research I 51:999-1015

Holm-Hansen O, Lorenzen C, Holmes R, Strickland J (1965) Fluorometric determination of chlorophyll. J Cons Perm Int Explor Mar Sci Commun 30:3-15

Huisman J, van Oostveen P, Weissing F (1999) Critical depth and critical turbulence: Two different mechanisms for the development of phytoplankton blooms. Limnology and Oceanography $44(7): 1781-1787$

Lazzara L, Bricaud A, Claustre H (1996) Spectral absorption and fluorescence excitation properties of phytoplanktonic populations at a mesotrophic and an oligotrophic site in the tropical north atlantic (eumeli program). Deep Sea Research Part I: Oceanographic Research Papers 43(8):1215 - 1240, DOI http://dx.doi.org/10.1016/0967-0637(96)00057-X, URL http://www.sciencedirect.com/science/article/pii/096706379600057X

Lefevre D, Minas H, Minas M, Robinson C, Williams PLB, Woodward E (1997) Review of gross community production, primary production, net community production and dark community respiration in the gulf of lions. Deep Sea Research Part II: Topical Studies in Oceanography 44(3):801 - 832, DOI http://dx.doi.org/10.1016/S0967-0645(96)00091-4, URL http://www.sciencedirect.com/science/article/pii/S0967064596000914

Lévy M (2008) The modulation of biological production by oceanic mesoscale turbulence. In: Weiss J, Provenzale A (eds) Transport and Mixing in Geophysical Flows, Lecture Notes in Physics, vol 744, Springer Berlin / Heidelberg, pp 219-261

Lévy M, Ferrari R, Franks PJS, Martin AP, Rivière P (2012) Bringing physics to life at the submesoscale. Geophysical Research Letters 39(14):L14602, DOI 10.1029/2012GL052756

Mahadevan A (2016) The impact of submesoscale physics on primary productivity of plankton. Annual Review of Marine Science 8(1):161-184, DOI 10.1146/annurev-marine-010814-015912, URL http://dx.doi.org/10.1146/ annurev-marine-010814-015912, pMID: 26394203, http://dx.doi.org/10.1146/ annurev-marine-010814-015912

Mahadevan A, Tandon A (2006) An analysis of mechanisms for submesoscale vertical motion at ocean fronts. Ocean Modelling 14(3-4):241-256

Mahadevan A, D'Asaro E, Lee C, Perry M (2012) Eddy-driven stratification initiates north atlantic spring phytoplankton blooms. Science 336(6090):54-58

McGillicuddy J DJ (2016) Mechanisms of physical-biological-biogeochemical interaction at the oceanic mesoscale. Annual Review of Marine Science 8:125-159, DOI 10.1146/ annurev-marine-010814-015606, URL https://www.scopus.com/inward/record.uri?eid= 2-s2.0-84954231340\&partnerID=40\&md5=bdf 3294183e54575b27558a8b9cef9ef, cited By 5

Mignot A, Claustre H, Uitz J, Poteau A, D'Ortenzio F, Xing X (2014) Understanding the seasonal dynamics of phytoplankton biomass and the deep chlorophyll maximum in oligotrophic environments: A bio-argo float investigation. Global Biogeochemical Cycles 28(8):856-876, DOI 10.1002/2013GB004781, URL http://dx.doi.org/10.1002/ 2013GB004781, 2013GB004781

Moran XAG, Taupier-Letage I, Vazquez-Dominguez E, Ruiz S, Arin L, Raimbault P, Estrada M (2001) Physical-biological coupling in the algerian basin (sw mediterranean) : Influence of mesoscale instabilities on the biomass and production of phytoplankton and bacterioplankton. Deep-sea research I 48:405-437

Morel A, Andrè JM (1991) Pigment distribution and primary production in the western Mediterranean as derived and modeled from coastal zone color scanner observations. Journal of Geophysical research 96:685-698

Mousing EA, Richardson K, Bendtsen J, Cetini I, Perry MJ (2016) Evidence of small-scale spatial structuring of phytoplankton alpha- and beta-diversity in the open ocean. Journal of Ecology pp n/a-n/a, DOI 10.1111/1365-2745.12634, URL http://dx.doi.org/10.1111/ 1365-2745.12634

Navarro G, Ruiz J (2013) Hysteresis conditions the vertical position of deep chlorophyll maximum in the temperate ocean. Global Biogeochemical Cycles 27(4):1013-1022, DOI 10.1002/gbc.20093, URL http://dx.doi.org/10.1002/gbc. 20093, 2012GB004396

Oguz T, Macías D, Tintoré J (2014) Impacts of boundary current instabilities on plankton production characteristics of the catalano-balearic sea (western mediterranean). Ocean Modelling submitted manuscript

Pascual A, Ruiz S, Olita A, Troupin C, Claret M, Casas B, Mourre B, Poulain PM, TovarSanchez A, Capet A, Mason E, Allen J, Mahadevan A, J T (2017) A multiplatform experiment to unravel meso- and submesoscale processes in an intense front (alborex). Front Mar 
Sci 4:39, DOI doi:10.3389/fmars.2017.00039

Platt T (1986) Primary production of the ocean water column as a function of surface light intensity: algorithms for remote sensing. Deep Sea Research Part I: Oceanographic Research 33:149-163, DOI 10.1016/0198-0149(86)90115-9

Platt T, Caverhill C, Sathyendranath S (1991) Basin-scale estimates of oceanic primary production by remote sensing: the north atlantic. Journal of Geophysical Research 96(C8):15,147-15,159, URL https://www.scopus.com/inward/record.uri?eid= 2-s2.0-0026268345\&partnerID=40\&md5=bf a4f4537db70e6471fa686025861627, cited By 145

Poulain PM, Barbanti R, Font J, Cruzado A, Millot C, Gertman I, Griffa A, Molcard A, Rupolo V, Le Bras S, Petit de la Villeon L (2007) Medargo: a drifting profiler program in the mediterranean sea. Ocean Science 3(3):379-395, DOI 10.5194/os-3-379-2007, URL http://www.ocean-sci.net/3/379/2007/

Raimbault P, Coste B, Boulhadid M, Benyahia B (1993) Origin of high phytoplankton concentration in deep chlorophyll maximum $(\mathrm{dcm})$ in a frontal region of southwestern mediterranean sea (algerian current). Deep-Sea Research I 49:791-804

Rodríguez J, Blanco JM, Jiménez-Gómez F, Echevarría F, Gil J, Rodríguez V, Ruiz J, Bautista B, Guerrero F (1998) Patterns in the size structure of the phytoplankton community in the deep fluorescence maximum of the alboran sea (southwestern mediterranean). Deep Sea Research Part I: Oceanographic Research Papers 45(10):1577 - 1593, DOI http://dx.doi.org/10.1016/S0967-0637(98)00030-2, URL http://www.sciencedirect.com/ science/article/pii/S0967063798000302

Ruiz S, Pascual A, Casas B, Poulain P, Olita A, Troupin C, Torner M, Allen J, Tovar-Sánchez A, Mourre B, Massanet A, Palmer M, Margirier F, Balaguer P, Castilla C, Claret C, Mahadevan A, Tintoré (2015) Report on operation and data analysis from multi-platform synoptic intensive experiment (alborex). Tech. rep., D3.8 Policy-oriented marine Environmental Research in the Southern European Seas

Ruiz S, Claret M, Pascual A, Olita A, Troupin C, Capet A, Tovar-Sanchez A, Allen J, Poulain PM, Tintoré J, Mahadevan A (2017) Effects of oceanic meso- and submeso-scale frontal processes 1 on the vertical transport of phytoplankton. Nature Communications, submitted

Siswanto E, Ishizaka J, Yokouchi K (2005) Estimating chlorophyll-a vertical profiles from satellite data and the implication for primary production in the Kuroshio front of the east china sea. Journal of Oceanography 61(3):575-589, DOI 10.1007/s10872-005-0066-7, URL http://dx.doi.org/10.1007/s10872-005-0066-7

Soetaert K, Petzoldt T (2010) Inverse modelling, sensitivity and monte carlo analysis in $\mathrm{r}$ using package fme. Journal of Statistical Software 33(3):1-28, URL https://www. scopus. com/inward/record.uri?eid=2-s2.0-77953156810\&partnerID= 40\&md5 $=\mathrm{a} 81 \mathrm{a} 3 \mathrm{c} 884 \mathrm{f} 59 \mathrm{de} 1454 \mathrm{e} 0 \mathrm{ffda} 979 \mathrm{fc02a}$, cited By 97

Sverdrup H (1953) On conditions for the vernal blooming of phytoplankton. J Cons Int Explor Mer 18:287295

Taylor JR, Ferrari R (2011a) Ocean fronts trigger high latitude phytoplankton blooms. Geophysical Research Letters 38:L23601, DOI 10.1029/2011GL049312

Taylor JR, Ferrari R (2011b) Shutdown of turbulent convection as a new criterion for the onset of spring phytoplankton blooms. Limnology and Oceanography 56(6):2293-2307, DOI 10.4319/lo.2011.56.6.2293

Tintoré J, La Violette P, Blade I, Cruzado A (1988) A study of an intense density front in the eastern alboran sea: the almeria-oran front. Journal of Physical Oceanography 18(10):13841397

Varela R, Cruzado A, Tintoré J, Garcia Ladona E (1992) Modelling the deepchlorophyll maximum: a coupled physical- biological approach. Journal of Marine Research 50(3):441-463, URL https://www.scopus.com/inward/record.uri?eid=2-s2 . 0-0027010940\&partner ID=40\&md5=1bf725c26b38a5d441d1b785f ebbf296, cited By 51

Videau C, Sournia A, Prieur L, Fiala M (1994) Phytoplankton and primary production characteristics at selected sites in the geostrophic almeria-oran front system (sw mediterranean sea). Journal of Marine Systems 5(3):235 - 250, DOI http://dx.doi.org/10. 1016/0924-7963(94)90049-3, URL http://www.sciencedirect.com/science/article/pii/ 0924796394900493

Zielinski O, Oschlies OLA, Reuter R (2002) Underwater light field and its effect on a onedimensional ecosystem model at station estoc, north of the canary islands. Deep Sea Research Part II: Topical Studies in Oceanography 49(17):3529 - 3542, DOI http://dx.doi.org/ 10.1016/S0967-0645(02)00096-6, URL http://www.sciencedirect.com/science/article/ 
